\title{
Technical Overview of the Net Metering in Lebanon
}

\author{
Issam Shabani*, Mohammad Chaaban* \\ Department of Industrial Engineering, Faculty of Technology, Lebanese University, Lebanon
}

Received October 6, 2020; Accepted October 21, 2020; Published October 28, 2020

\begin{abstract}
In order to realize the best practices to allow the individuals participate in renewable energy production, a collection of legislation was ratified, and a set of decisions was introduced to encourage the prosumer concept. This notion, which is called Net Metering (NEM), is a billing mechanism that credits PV solar system owners for the energy injected to the grid. Lebanon adopts the NEM policy to reduce the demand and boost the grid through increasing the generation capacity. The decline of solar equipment cost encourages people to subscribe to the NEM service by utilizing the PV solar systems. The implementation of the NEM service provides the customers with leverage over their electricity bills. However, connecting the home micro grid into the vast grid is not easy. It imposes many technical challenges which are discussed in this article.
\end{abstract}

Keywords: Net Metering; Solar PV System; Renewable Energy Resources; Sustainable Energy; On-Grid System; Hawaii Back Feed Problem

\section{Administrative Requirements}

A major support for the expansion of solar energy in Lebanon is the Net Metering NEM policy which has been adopted and approved by the Electricite du Liban (EDL) through Decision No. 318-32 / 2011. Its advantages include legal and technical simplicity, in addition to the free installation of the meter by EDL.

The currently available Net Metering scheme implemented in Lebanon allows the subscribers to reduce the monthly bills through 'net consumption' payments which are rolled over to the next billing cycle - in case of surplus - until the end of the fiscal / calendar year. And then EDL will reset the counter to zero to start all over. In this case, any energy surplus is not financially remunerated, but is considered as a contribution to EDL's electricity production [1]. This implies that oversizing of the solar Photo Voltaic (PV) system to more than the average annual energy consumption will increase its initial cost, while the return will remain constant, subsequently raising the system's payback period.

\subsection{Subscription}

Any electricity subscriber can apply for energy NEM by filling out the net metering interconnection application (at the EDL website), and uploading it with all required documentation. Apart from the personal information, the application form includes the name of manufacturer and supplier, technical details of the components planned to be installed, as well as the contractor's name. Finally, the site drawing, single line diagram, and equipment data sheet are attached. 


\section{Technical Overview of NEM}

The useful benefit of the Renewable Energy System (RES) system is its capability to connect with the general electrical grid, which allows the owner to transfer surplus energy directly to the utility by using the NEM (Figure 1). All that you need in addition to the PV system installation is to replace the old unidirectional electromechanical meter with a new electronic bi-directional meter, which mounted by EDL after you have subscribed to this service.

Each installation can differ depending on the RES used (such as PV, wind, biomass, and hybrid).

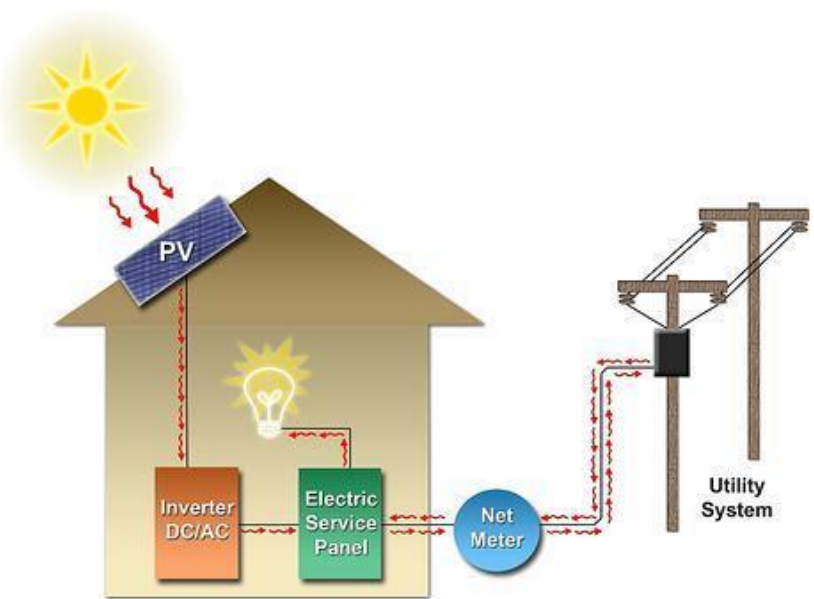

Figure 1. Residential Grid-Connected PV System with Net Metering (www.slideshare.net/RaghavGupta20/zero-energy-building, Public Domain)

\section{Applicable Standards}

In order to ensure the installation's protection and safety from hazards, in addition to proper performance and efficiency, the PV installations should be in compliance with regulations (national or international regulations) and comply with different standards according to the country/region in which it is used. In the Lebanese context, inverters made in Europe are more common. However, a review of the applicable standards will help inform the decision-making process [2]. Lebanon has adopted the European standards that cover all issues related to PV systems and the NEM, such as the safety of power converters, environmental testing, measurement of photovoltaic current-voltage characteristics, the procedure for measuring efficiency, and characteristics of the utility interface (Figure 2).

Lebanon implemented the following European Standards (EN), VDE (part of the German standards collection) and IEC (The International Electro Technical Commission):

$\checkmark \quad$ IEC 61683: Photovoltaic systems - Power conditioners - Procedure for measuring efficiency.

$\checkmark$ IEC 61727: Photovoltaic (PV) systems - Characteristics of the utility interface.

$\checkmark$ IEC 62109-1-2: Safety of power converters for use in photovoltaic power systems. 
IEC 62116: Utility-interconnected photovoltaic inverters - Test procedure of islanding prevention measures.

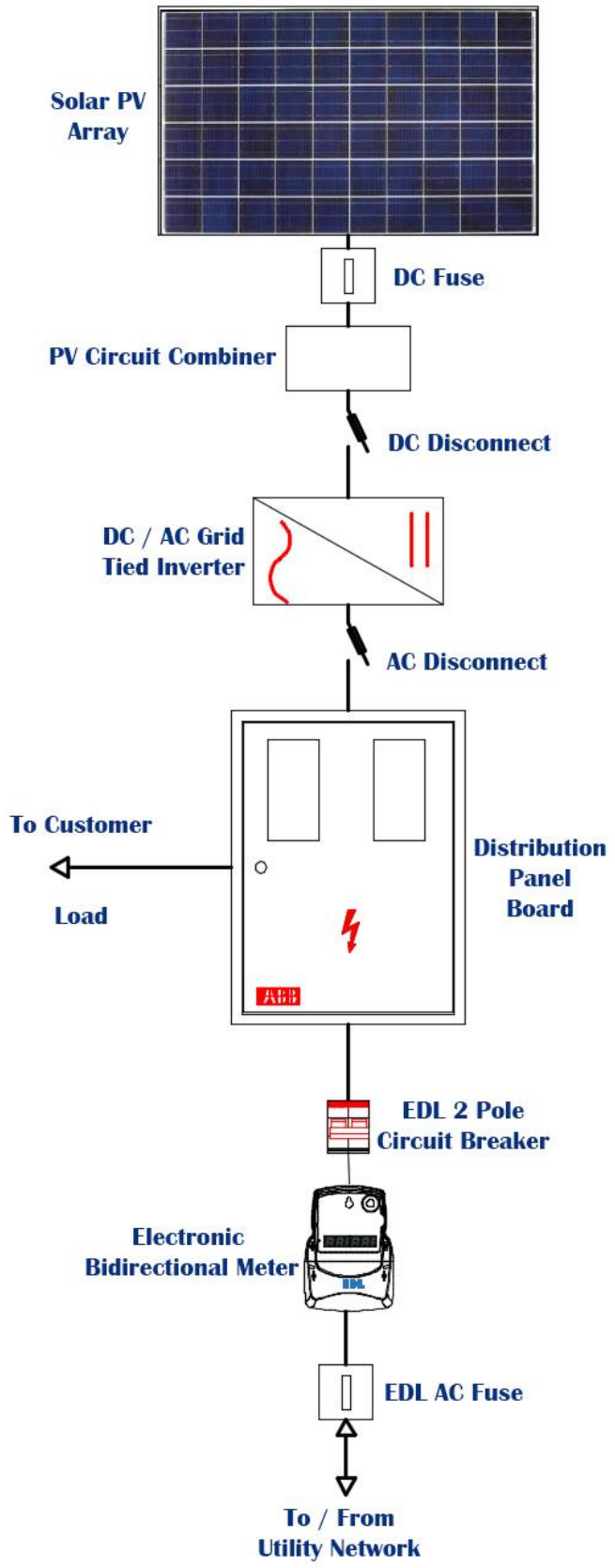

Figure 2. Single line diagram for NEM interconnection with no battery backup

$\checkmark$ IEC 60068-2-5: Environmental testing - Part 2-5. Simulated solar radiation at ground level and guidance for solar radiation testing.

$\checkmark$ IEC 60364-7-712: Electrical installations of buildings - Part 7-712. Requirements for special installations or locations - Solar photovoltaic (PV) power supply systems.

$\checkmark$ IEC 60904-1: Photovoltaic devices - Part 1. Measurement of photovoltaic current-voltage characteristics. 
$\checkmark \quad$ IEC 61683: Photovoltaic systems - Power conditioners - Procedure for Measuring efficiency

$\checkmark$ IEC 61000-4-30: The method of measurement of grid quality parameters: frequency, voltage, harmonics, unbalance and flicker.

$\checkmark$ IEC 61724: Photovoltaic system performance monitoring-Guidelines for measurement, data exchange and analysis.

$\checkmark$ IEC 61727: Photovoltaic (PV) systems - Characteristics of the utility interface.

$\checkmark$ IEC 61730-2: Photovoltaic (PV) module safety qualification - Part 2. Requirements for testing.

$\checkmark$ IEC 61730-2: Photovoltaic (PV) module safety qualification - Part 2. Requirements for testing.

$\checkmark$ IEC 62670-1: Photovoltaic concentrators (CPV) - Performance testing - Part 1.Standard conditions.

$\checkmark$ IEC 62670-2: Photovoltaic concentrators (CPV) - Performance testing - Part 2. Energy measurement.

$\checkmark$ VDE V 0126-1-1: Automatic disconnection device between a generator and the public low-voltage grid.

$\checkmark$ EN 50438: Requirements for micro-generating plants to be connected in parallel with public low-voltage distribution networks.

\section{Controllers}

If you install an off-grid Renewable Energy System (e.g., wind and PV) with a battery attached, you will need a charge controller. In our study, we mainly refer to PV charge controllers or solar charge regulators. The purpose of using them is to control the power from the solar array entering the battery bank. For this function, the controller is one of the most critical components in any power system.

The controllers protect the batteries from:

$\checkmark$ Over Charging: A PV controller prevents overcharging of batteries by reducing the flow of energy to them (i.e., opening the circuit between the battery and the PV array). Once a certain preset voltage is reached, this predetermined voltage can be adjusted by some types of controllers. If the voltage drops when the load increases, the controller will allow charging, which is known as voltage regulation.

$\checkmark$ Over Discharging: Low Voltage Disconnect (LVD) circuit (included in the controller) will disconnect all loads when the battery discharges about $80 \%$ of its total capacity. This feature protects the batteries from complete discharge which damages them and reduces their lifespan. At night, in the absence of solar irradiation, the controller intervenes to prevent the current from flowing in the reverse direction, causing the batteries to drain.

Before purchasing a new controller, you may try to select it according to:

Adjustable set points - over current protection - reverse current protection - high / low voltage warning and protection, etc.

When a homeowner decides to install an on-grid PV solar system with a storage battery bank, there is no need to install a charge controller. Because the Grid-Tie Inverter is sufficient to direct the excess charge to the grid and protect the batteries from overcharging. 
For the off-grid system, there are two types of charge controllers to consider: Pulse Width Modulation (PWM) controllers, and Maximum Power Point Tracking (MPPT) controllers.

\subsection{Pulse Width Modulation (PWM) Technique}

The Pulse Width Modulation (PWM) charge controller is used instead of the OnOff charging mode (old idea) which causes the battery plates to sulfate and reduces the nominal battery capacity by $55 \%$ to $60 \%$ after one year of usage. Sulfation happens inside lead-acid batteries when the electrolyte starts to break down due to incorrect charging levels and settings.

PWM charge controllers are solid state controllers that use a semiconductor switching element between the PV array and the battery. This element is switched on/off by PWM at a variable frequency determined by the variable duty cycle to maintain the battery at or very close to the voltage regulation set point. At this point the charging algorithm slowly reduces the charging current to avoid heating and gassing of the battery [3]. The charging cycle process continues to provide the battery with the full amount of energy in the shortest possible period. This results in improved overall performance, and a healthy battery with a longer life span.

PWM controllers are ideally suitable for small solar systems with a few low voltage PV solar panels and a small battery. They are simpler than MPPT controllers, and therefore typically less expensive.

\subsection{Maximum Power Point Tracking (MPPT)}

The extraction of the maximum available power from a photovoltaic module and substantially increasing the efficiency can be done by using the Maximum Power Point Tracking (MPPT) Controller [4]. Solar MPPT charge controllers are DC to DC converters that detect and convert the PV generated voltage to a more suitable one in real time basis. This operation can be achieved by tracking the maximum voltage-current (VI) value so that the system can charge the battery bank with the optimum power output (Figure 3 ).

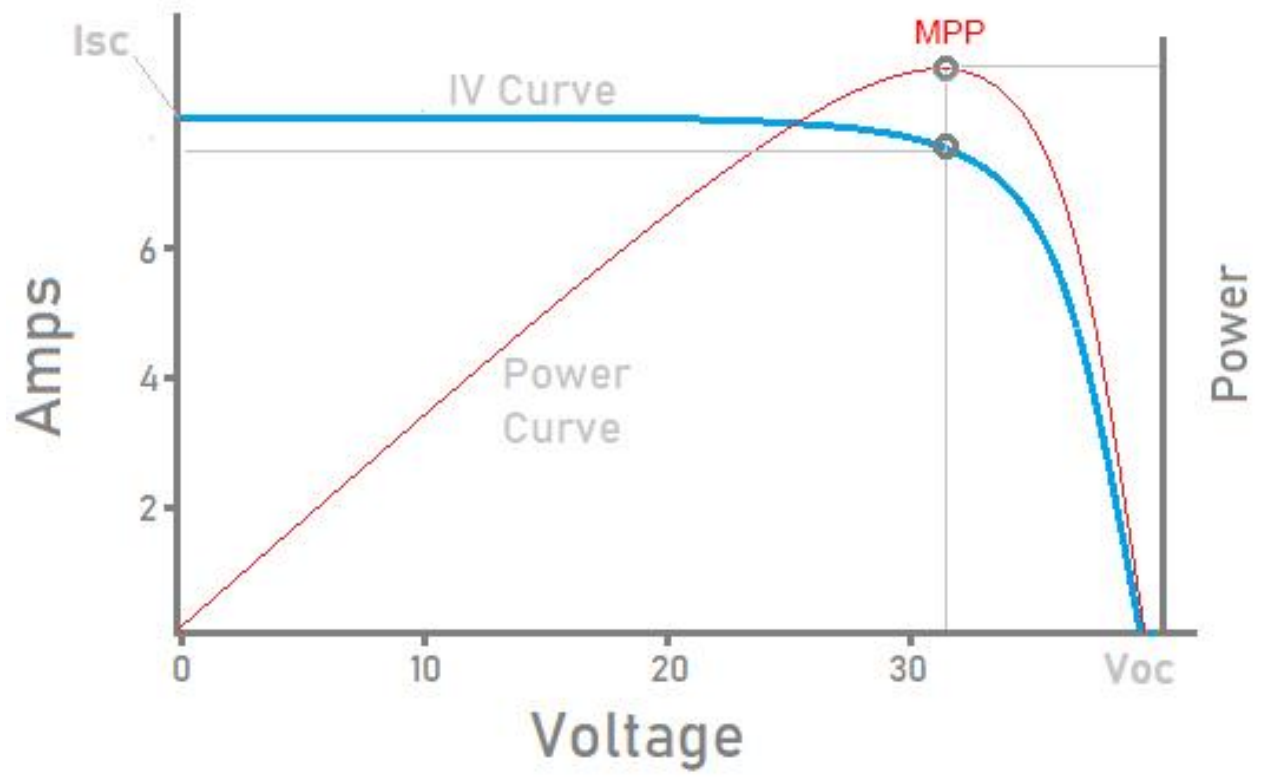

Figure 1. Current-Voltage-Power Characteristic Curve of a PV Module 
The output power from the PV system is influenced by the weather conditions (i.e., MPP is not fixed), and the maximum power varies proportionally with solar radiation and inversely with ambient temperature (non-linear relation). The MPPT charge controller is more effective and provides more power under these conditions:

$\checkmark$ Cloudy or hazy ambient (very low irradiance).

$\checkmark$ Cold days.

$\checkmark$ The solar cell temperature is below $45^{\circ} \mathrm{C}$ or above $75^{\circ} \mathrm{C}$.

As a result, using the MPPT controller gives you a $20 \%$ to $45 \%$ power gain in winter and $10-15 \%$ in summer and cost more money.

\subsection{MPPT vs. PWM Controllers Economic Evaluation}

The function of the solar charge controller is to regulate the power provided to the batteries from the PV panels. Overloading batteries can reduce the battery life and in some cases destroy them. PWM and MPPT solar charge controllers are commonly used to charge batteries with the solar power.

In the example below, a common 60 cell Polycrystalline Silicon PV panel with an operating voltage of $31.1 \mathrm{~V}$ and current $8.37 \mathrm{~A}$ is connected to a $12 \mathrm{~V}$ battery (Figure 4). To compare the performance of different types of controllers, we will use:

$>$ PWM charge controller (1st case), with a price of $45 \$$ in the Lebanese market.

$>$ MPPT charge controller (2nd case), with a price of $140 \$$ in the Lebanese market.

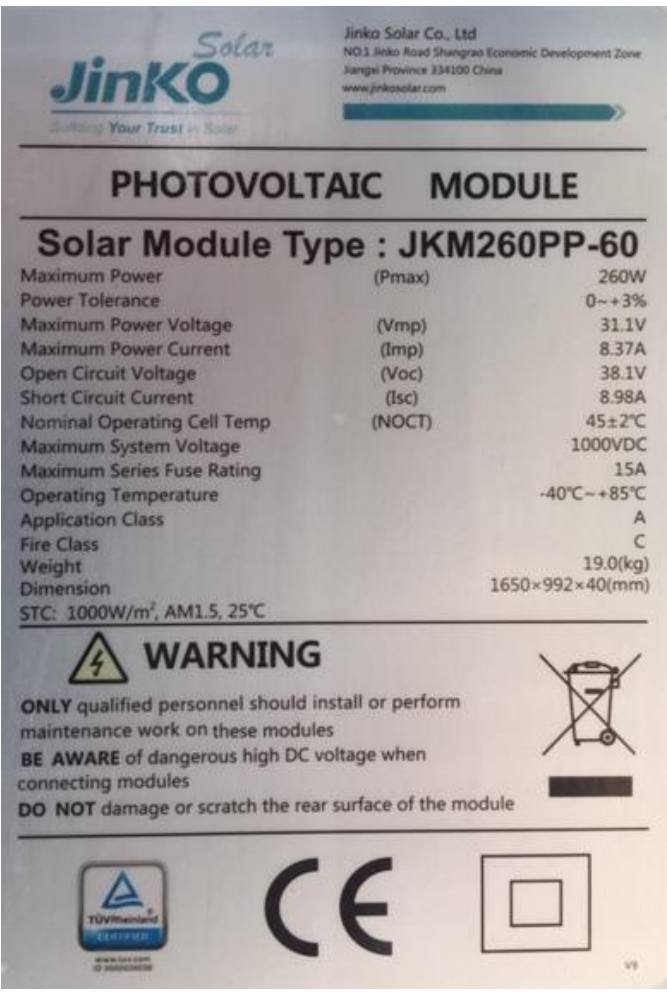

Figure 2. Polycrystalline Silicon PV panel

1st Case: PWM 
Using the PWM charge controller (Figure 5), the panel voltage drops to $12 \mathrm{~V}$ to match the battery voltage, and as a result the power output is reduced to $8.37 \mathrm{~A} \times 12 \mathrm{~V}=$ $100 \mathrm{~W}$.
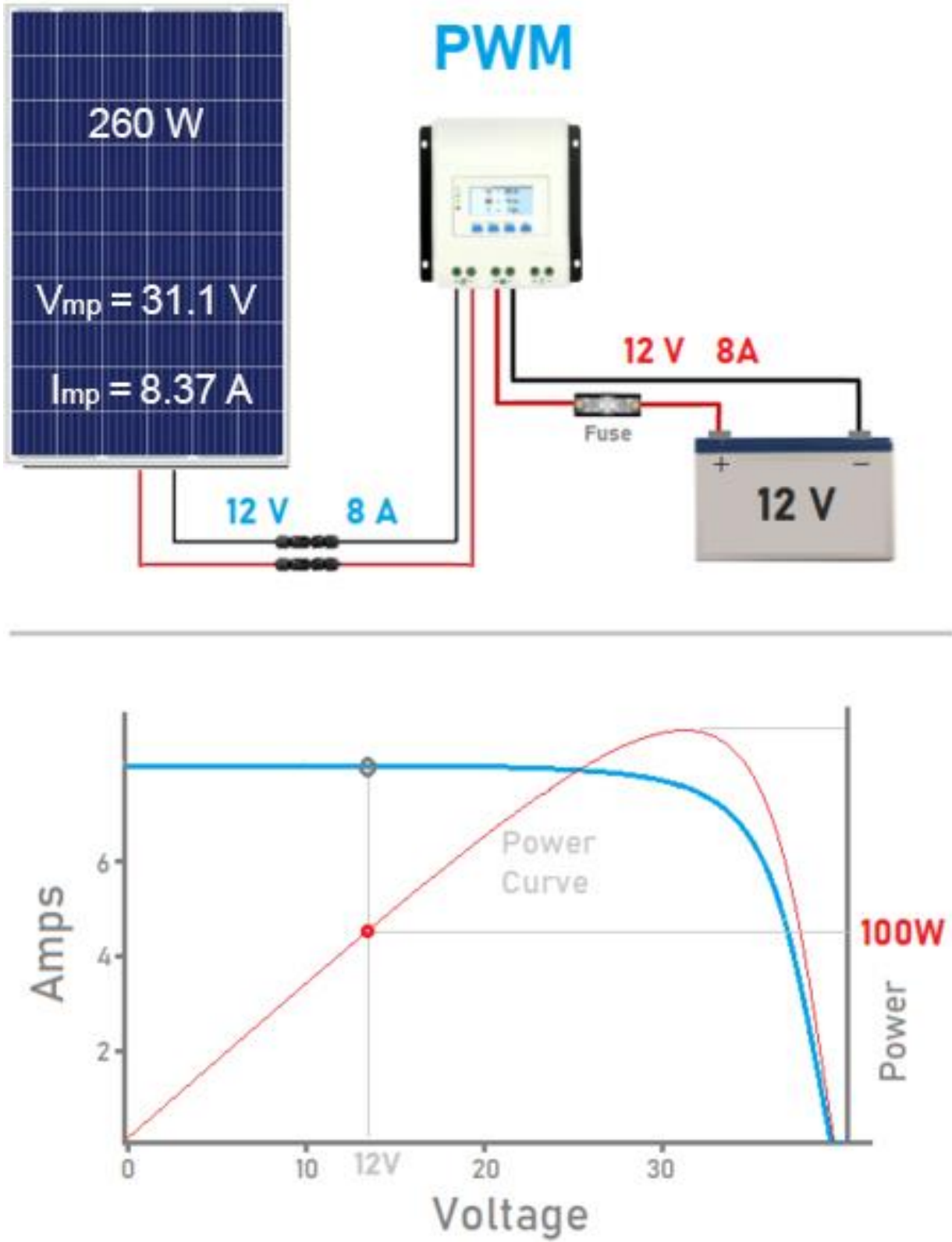

Figure 5. Power Drawn from PV Panel when Using PWM Controller.

2nd Case: $M P P T$

Using the MPPT charge controller, the PV panel can operate at its maximum power point (MPP), and produce much more power (Figure 6).

The power drawn from the panel is $8.37 \mathrm{~A} \times 31.1 \mathrm{~V}=260 \mathrm{~W}$. 

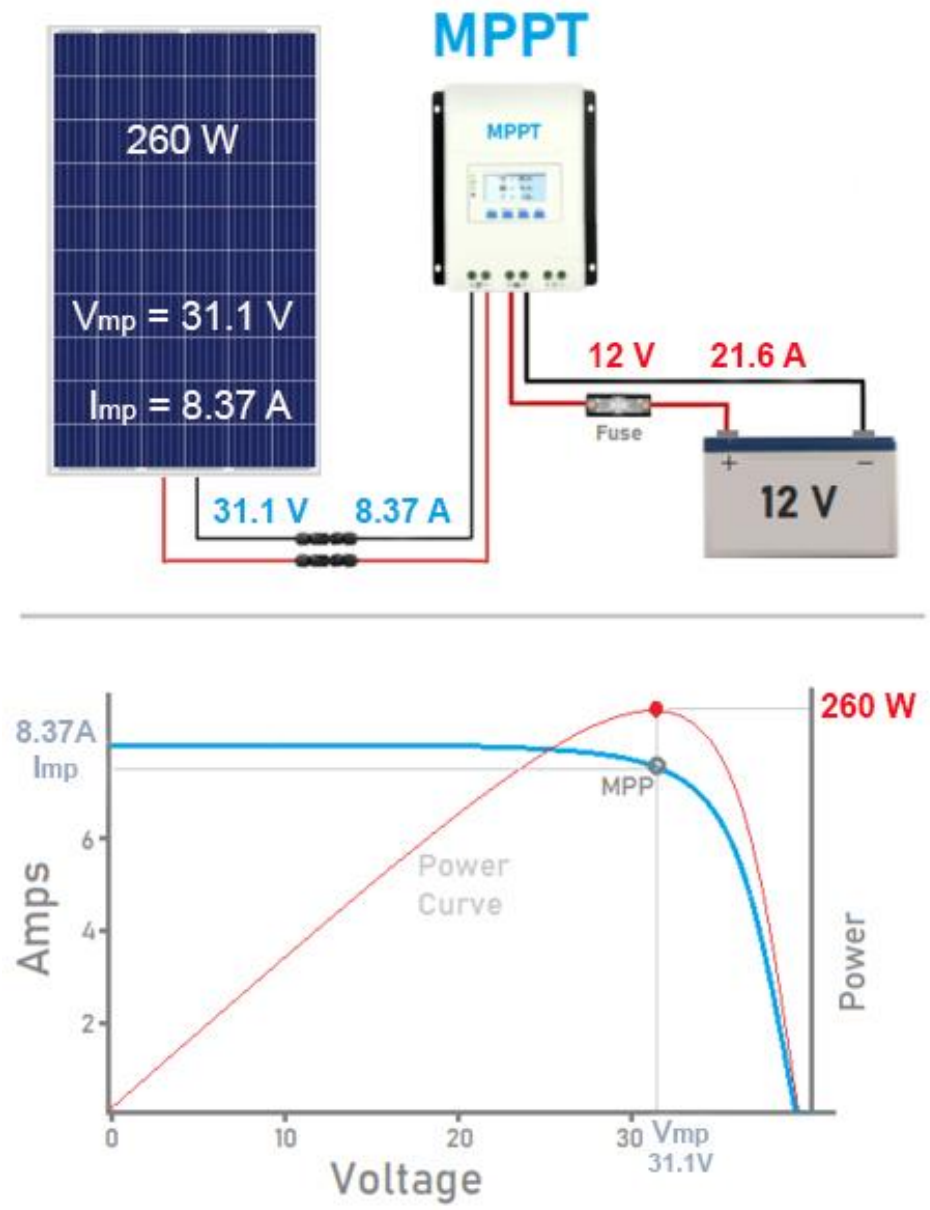

Figure 6. Power Drawn from PV Panel when Using MPPT Controller

To compare the obtained results, some assumptions are made (Table 1):

- The PV panel is in full sun.

- Controllers run with the maximum capacity.

- Ignore the presence of wires voltage drop.

- Continuous loading prevents the battery from a full charge.

- No maintenance needed for the controllers.

- The average daily sun is 6 hours (daily charging time).

- Sunny days are 300 days/year.

Daily $\Delta P=\frac{(100 W * 6 \text { hours }) / 1000}{(260 W * 6 \text { hours }) / 1000} \times 100=38.4 \%$

The MPPT controller is better than the PWM controller by $38.4 \%$.

Annual energy charged to the battery $(\mathrm{PWM})=100 \mathrm{~W} \times 6$ hours $\times 300$ days $=180 \mathrm{kWh}$. Annual energy charged to the battery $($ MPPT $)=260 \mathrm{~W} \times 6$ hours $\times 300$ days $=468 \mathrm{kWh}$.

Average EDL electrical energy price $=9.5 \mathrm{cent} / \mathrm{kWh}$.

Energy savings per year $=468 \mathrm{kWh}-180 \mathrm{kWh}=288 \mathrm{kWh}$ annually.

Annual Savings $=288 \mathrm{kWh} \times 9.5 \mathrm{cent} / \mathrm{kWh}=27.36 \$$ annually.

Simple Payback Period $(\mathrm{SPB})=\frac{\text { Initial Investement }}{\text { Annual Net Savings }}=\frac{120 \$}{27.36 \$} \cong 4.4$ years. 
The latter analysis clearly indicates that using an MPPT controller improves energy harvesting by $38.4 \%$. The MPPT controller may be a little bit expensive, but it does have a better efficiency, resulting in a valuable savings of about 27.36 \$/year. Finally, the 4.4 years SPB indicates that this investment is feasible, knowing that the average lifespan period of the system is 25 years.

Table 1. Comparing MPPT and PWM controllers.

\begin{tabular}{|l|}
\hline \multicolumn{1}{|c|}{ MPPT Type Solar Controllers } \\
\hline $\begin{array}{l}\text { Algorithm included in the controller } \\
\text { used to track maximum available } \\
\text { power from the module. }\end{array}$ \\
\hline $\begin{array}{l}\text { New technology with increase in } \\
\text { charging efficiency about } 30 \% .\end{array}$ \\
\hline $\begin{array}{l}\text { More expensive (2 - } 3 \text { times price of a } \\
\text { comparable PWM controller). }\end{array}$ \\
\hline $\begin{array}{l}\text { more sophisticated (more electronic } \\
\text { components). }\end{array}$ \\
\hline Better in cool climate. \\
\hline $\begin{array}{l}\text { Shorter lifespan due to greater thermal } \\
\text { stress. }\end{array}$ \\
\hline $\begin{array}{l}\text { Used when solar array voltage is } \\
\text { higher than the battery voltage. } \\
\text { Bigger in physical size, used for large } \\
\text { systems. }\end{array}$ \\
\hline
\end{tabular}

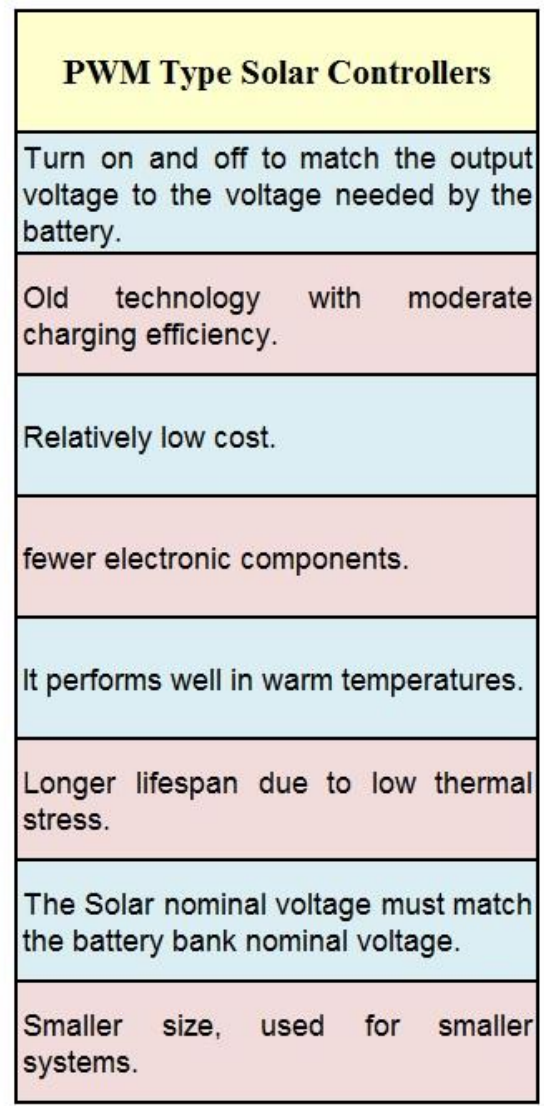

\section{Inverters}

There are two main operation modes of inverters, namely stand-alone (or off-grid) inverter, and grid connected (or grid-tie) inverter.

\subsection{Stand-Alone Inverter}

The stand-alone or off-grid power inverter is an electronic device that converts direct current (DC) from the battery to alternating current (AC) used by common appliances. Their size and rating range from a few hundred watts (small appliances) to megawatts, depending on the intent of use.

The main function of the inverter is to keep a constant voltage on the AC side and convert the input power, $P_{\text {in }}$ into the output power, $P_{\text {out }}$ with the highest possible efficiency [5], given by: 
$\eta_{\text {inv }}=\frac{P_{o u t}}{P_{\text {in }}}=\frac{V_{a c} I_{a c} \cos \varphi}{v_{d c} I_{d c}}$

where

$\cos (\varphi)=$ power factor

$I_{\mathrm{dc}}=$ current required by the inverter from the DC side, i.e., controller (A).

$V_{\mathrm{dc}}=$ input voltage for the inverter from the DC side, i.e., controller (V).

The quality of the inverter output waveform determines its performance. Normally, a sinusoidal waveform provides the best efficiency. There are three major different types of inverters, based on the shape of their output waveform:

$\checkmark$ Square Wave Inverter.

$\checkmark$ Modified Sine Wave Inverter.

$\checkmark$ Sine Wave Inverter.

\section{Square Wave Inverter}

The square wave inverter is the simplest among all types. It is also the cheapest type of inverters, and least used. A simple oscillator can be used to produce square wave voltage. This waveform can run simple devices with a universal motor.

Most of the appliances are designed to use the sine waveform supply. If they are powered by a square wave, they can:

Get hot- buzz or make annoying humming noise - operate with very high losses - may be damaged. For these reasons, the square wave inverters are banned in a few European countries.

\section{Modified Sine Wave}

A modified sine wave or quasi sine wave inverter is designed to simulate a real sine wave, since the generation of the sine waves is expensive. It has a waveform more like a square, but with an extra step. It can operate most appliances but with reduced efficiency. Most motors will use about $20 \%$ more power and may create humming noises.

\section{Sine Wave}

"Pure" or "real" sine wave inverters are capable of simulating precisely the AC power that is generated by rotating AC machinery and are therefore supplied by the local utility company. This waveform is ideal for transforming the AC power with minimum harmonic distortion. The main benefit of this inverter is that most electrical and electronic appliances and equipment are designed to work well using sine-wave. Generally speaking, because of the additional circuitry, sine wave inverters are usually more costly (from 2 to 3 times) than other types.

\section{Sizing Stand-Alone Inverter}

The size of the stand-alone (off-grid) inverter depends on the total power of the connected appliances, which can be achieved by simply adding the rating of each connected device. If an electrical motor is attached, a high starting current is drawn for a limited time interval, so this should be taken into consideration when choosing the correct inverter protection. It shall be known that they are designed to withstand a surge for a few seconds. 


\subsection{Grid-Tie Inverter (GTI)}

Unlike the stand-alone solar systems, on-grid PV systems are connected to the public network without the need for electrical storage devices (i.e., virtually the grid is your battery). Any excess power that is not consumed by your electrical loads is exported into the utility company grid, which causes the meter to spin backward. Usually, you get returns for this energy.

The key role of the grid-interactive or synchronous inverters or simply the grid-tie inverter (GTI) is to synchronize the phase, voltage, and frequency of the power line with that of the grid $(50 \mathrm{~Hz}$ grid frequency and $220 \mathrm{~V}$ root mean square voltage - nominal values of Lebanon electrical grid). When this matching happens, you can never notice anything. Similar to any dynamic system, the power system is continuously subjected to perturbations and experiences transitions from one operating point to another in the form of oscillations. Voltage stability, frequency stability, and inter-area oscillations have become greater concerns than in the past [6]. At any moment, the output voltage remains slightly higher than the grid voltage, so that excess electricity flows towards the grid.

A high-quality modern GTI has a fixed unity power factor, which means its output voltage and current are perfectly lined up and its phase angle is within 1 degree of the AC power grid. The GTI has an on-board computer that senses the current AC grid waveform, and outputs a voltage to correspond with the grid [7]. For these reasons, GTIs have various technical specifications and a complex constructional architecture that justifies their high price which is about three times the stand-alone inverter.

\section{$\underline{\text { Installation Location }}$}

Like all electronic devices, GTIs run more efficiently in a cool environment. In order to optimize its lifetime and performance, the installation place should have the following specifications:

$>$ Easily accessible cool spot.

$>$ Away from direct sunlight

$>$ Good ventilation.

$>$ Away from moisture (dry place).

$>$ Dust-free locked room.

Most of these mentioned requirements are not always available. As a result, the majority of GTIs are designed for outdoor use, with protection from rain, sleet, snow, water splashing, dust, and corrosion with optimum Ingress Protection (IP 65) ${ }^{1}$. Ingress Protection rating, which is established by international standards, describes the level of sealing effectiveness of the enclosure against foreign bodies such as moisture and dust.

\section{Sizing Grid-Tie Inverter}

The size of the Grid-Tie inverter can be determined by knowing how much power will be drawn from PV panels or other RES such as wind turbines. It should take into consideration the surge (peak power produced by the solar system), which accounts for around $25 \%$ of the total power of the solar array.

There is no need to install charge controllers or battery banks in a grid-tied network but use GTIs instead. They are connected directly to the main grid and transform the DC power from a PV system to the AC power, thereby supplying power to the main grid and 
reducing the electricity extracted from it. Some GTIs are hybrids which inject power to the grid and charge a battery bank for energy back up.

The output of a solar PV varies depending on the weather condition, irradiation, angle of incidence, and cell temperature. In order to maintain the efficient operation despite environmental variations, one approach is to use a maximum power point tracking (MPPT) algorithm to dynamically tune either control current or voltage to the maximum power operating point [8]. This feature is employed to optimize the system to work always at its maximum efficiency under any weather condition.

\subsection{Total Harmonic Distortion (THD)}

The phrase "Power Quality" has been widely used during the last decade and includes all aspects of events in the system that deviates from normal operation. However, it is more correct to distinguish between voltage and current quality, rather than power quality [9]. To improve the reliability of the grid, the wave distortions should be prohibited, which increase the peak current, reduce the power factor, and thus result in lower efficiency due to higher temperature.

In normal conditions, the output voltage form is a sinusoidal wave where THD is close to or equal to zero. THD is the percentage value between the total components of harmonics (voltage or current) with its fundamental components. The greater the percentage of THD, the greater the risk of equipment damage [10].

$$
\begin{aligned}
\text { THD } & =\sqrt{\sum_{h=2}^{h}\left(\frac{Q_{h}}{Q_{1}}\right)^{2}} \\
& =\frac{\sqrt{\left(V_{2}+V_{3}+V_{4}+\cdots \ldots V_{h}\right)^{2}}}{V_{1}} * 100 \%
\end{aligned}
$$

where

Q represents either current or voltage.

$\mathrm{Q}_{1}=$ r.m.s. value of the fundamental component.

$\mathrm{h}=$ harmonic order. Harmonic: is a multiple of the basic frequency $50 \mathrm{~Hz}$; the $2 \mathrm{nd}$

harmonic is at $100 \mathrm{~Hz}$; the 3rd harmonic at $150 \mathrm{~Hz}$, etc. These harmonic waveforms are added to the basic which creates a distorted sine wave.

$\mathrm{Q}_{\mathrm{h}}=$ r.m.s. value of the harmonic component of order $\mathrm{h}$.

The nominal output voltage waveform of the PV power Plant shall be of 230/400 $\mathrm{V}, 50 \mathrm{~Hz}$, with a sinusoidal waveform complying with a THD $<5 \%$. For plants with an output current $\mathrm{I} \leqslant 16$ A per phase, the harmonic components of the current produced and measured at the output terminals shall comply with the standard IEC 61000-3-2 "Electromagnetic compatibility (EMC) - Part 3-2: Limits - Limits for harmonic current emissions (equipment input current $\leqslant 16$ A per phase)" . The limitation of voltage changes, voltage fluctuations, and flicker shall comply with the standard IEC 61000-3-3. For all the plants connected to the low voltage (LV) grid, the voltage quality measured at the Point of Connection shall be in accordance with the IEC 61000-2-2 "Compatibility levels for low-frequency conducted disturbances and signaling in public low-voltage power supply systems" and IEC/TR 61000-3-14 [2]. 


\subsection{Islanding}

Distributed Generation is a system that produces electricity near the consuming area. The condition of "Islanding" in Distributed Generators (DGs) is an electrical phenomenon that occurs when the energy supplied by the power grid is interrupted due to various factors and the DGs continue energizing some or the entire load. Thus, the power grid stops controlling this isolated part of the distribution system, which contains both loads and generation [11]. Islanding is often considered as an undesirable event because of the potential damage to existing equipment, utility liability concerns, reduction of power reliability, and power quality [12].

For these purposes, DGs systems must sense islanding and automatically (fast response time) detach it from the circuit; this is referred to as anti-islanding. GTIs were equipped with anti-islanding features to easily and quickly disconnect DG from the grid in order to reduce risks when the power grid goes down (blackout). It will shut down quickly to stop the electricity from passing through it to avoid harming any maintenance worker who is repairing the power grid and has the ability to restore its normal operation when the main grid is switched on again.

To prevent islanding, several detection methods have been used to monitor over/under voltage and over/under frequency. The European general practice is to keep PV inverters connected during minor faults in order to support the grid riding through voltage dips and operating at variable reactive power levels to maintain normal grid voltage [13]. According to the country or region, different standards have been adopted. The European standard is the guide in Lebanon. The licensed inverter should be compliant with the IEC 62116 standard (Utility-interconnected photovoltaic inverters - Test procedure of islanding prevention measures) and can be configured with the following parameters [14]: Loss of main detection limit of $300 \mathrm{~ms}$.

\section{Hybrid Solar Systems}

Most NEM subscribers do not use batteries, as the output of excess power generation goes to the grid. If the grid goes into power outage or becomes unstable (case repeated in Lebanon every day), your home will lose power, because the GTI will shut down entirely for safety reasons. To overcome the utility power failure problem, you can use a backup battery bank, and get power temporarily from batteries in a battery ready system.

Hybrid solar systems take the benefits of both grid-tied (NEM) and off-grid (battery bank charging) solar systems. To do so, you will need a special hybrid solar inverter or just connect a charge controller to the system. This type of inverter is capable of prioritizing various loads and different sources simultaneously (i.e., feeding the load and charging the battery at the same time).

Hybrid solar system's advantages:

$>$ Less expensive than the off-gird solar system since the capacity of the battery bank can be less than the peak requirements.

$>$ Keeping the power uninterrupted after the main grid failure (i.e., continuous power supply).

$>$ Benefits from the RES to the fullest because there is no waste of excess energy at the time of the blackout.

Hybrid solar system's disadvantages: 
Higher initial cost of batteries and hybrid solar inverter.

$>$ Higher maintenance expenses due to the presence of batteries.

$>$ Longer payback period after the relative rise in CAPEX and OPEX.

$>$ More complicated installation and wiring (need more room space).

\section{Energy Metering}

NEM allows energy to flow in two directions, i.e., from the customer side to the grid when the supply is excessive and from the grid to the customer side when the demand is greater than the RE production. Bidirectional utility meters adopted for the NEM service are capable of recording how much net power consumed from the EDL grid, but cannot tell users how much power consumed from the PV solar system. To know the quantity of power generated from the solar system, another separated energy meter is required to be installed at the PV panels output. In this case, a dual energy metering system is implemented.

\subsection{Standards and Norms}

The EDL accepted meters shall be designed, manufactured and tested in conformity with the latest IEC standards and/or the corresponding national standards. In case of any deviation, the vendor/manufacturer may propose equipment/material conforming to equivalent national standards. However, the provisions of following specifications shall supersede the provisions of these standards in case of any conflict.

IEC-62052-11: Electricity metering equipment (a.c.)- General requirements, tests and test conditions.

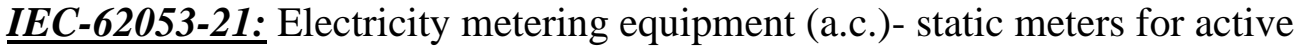
energy(classes 1and 2).

IEC-62054-21: Electricity metering - Tariff and load control - Particular Requirements for time switches.

IEC-62056-21: Electricity metering - Data exchange for meter reading, tariff and load control -Direct local data exchange.

$\underline{I E C-60695-2-10:}$ Fire hazard testing. Part-2 test methods glow wire test and guidance.

IEC-60947-7-1: Test requirements of Terminal Blocks.

IEC-62056-62: Electricity metering - Data exchange for meter reading, tariff and load control -Interface classes.

IEC-62056-42: Electricity metering - Data exchange for meter reading, tariff and load control -Physical layer.

IEC-62056-46: Electricity metering - Data exchange for meter reading, tariff and load control -Data link layer.

IEC-62056-53: Electricity metering - Data exchange for meter reading, tariff and load control -COSEM Application layer.

IEC-62056-61: Electricity metering - Data exchange for meter reading, tariff and load control -Object identification system (OBIS).

IEC-61334-4-41: Distribution Automation Using Distribution Line Carrier Systems-Part4. 


\subsection{Technical Specifications of Approved Energy Meter}

EDL approved the installation of the electronic energy meters (Circutor CIRWATT B series, made in Spain) into the NEM service customers system. These meters are intended for indoor installation and have the following specifications:

1. Single phase multi-function, multi tariff static meter with not less than four tariffs for $\mathrm{kWh}$ (daily, weekly, seasons, etc.), used for low voltage direct connection $1 \times 230$ volts 15/60 A, class (1) according to IEC 62053-21.

2. The meter has a reasonably dust-proof case, which can be sealed in such a way that the internal parts of the meter are accessible only after breaking the seals. The meter cover shall not be removable without removing seals and the use of a tool, and the base and cover materials should be quality insulating material (polycarbonate).

3. Minimum ambient temperature $-10^{\circ} \mathrm{C}$, maximum ambient temperature $45^{\circ} \mathrm{C}$, and 95\% humidity.

4. Rated frequency $50 \mathrm{~Hz}$, Rated voltage 230 volts, voltage variations $0.85 / 1.15$ of rated voltage, and rated current up to $60 \mathrm{~A}$.

5. The meter conformed to the degree of protection IP 51, as given in IEC 60529; the meters are well protected against moisture and direct entry by an excellent system of seals, gaskets, interlocking grooves, and channels moldings.

6. The meter data stored in non-volatile memory (EEPROM: Electrically Erasable Programmable Read-Only Memory) and can be read manually from the meter with a portable PC or a hand-held terminal. The meter has a memory sufficient to store at least 90 days of Load profile.

7. The meter incorporates a digital display unit, which displays: import active energy $\mathrm{kWh}$, export active energy kWh, current in Amp, Voltage, error code, date and time.

8. The configuration software runs on windows operating environment. This software has two level of permissions:

- Administrator level: the administrator can do all tasks and define Users and give them the permissions and tasks.

- Operator level: the operator can do only tasks determined by administrator.

\section{Summary and Technical challenges}

EDL is unable to meet the demand because of insufficient generation capacities, especially during peaks. Since it has high solar energy potential due to irradiation levels, Lebanon adopts the NEM policy to reduce the demand and boost the grid through increasing the generation capacity. The decline of solar equipment cost, encourage people to subscribe to the NEM service by utilizing the PV solar systems. The implementation of the NEM service gives the customer some leverage over his electricity bill, but too many administrative and financial steps are required to apply. Connecting your home micro grid into the vast grid is not easy; but rather imposes many technical challenges.

\subsection{Frequent Power Outages}

When the grid goes into power blackout, your home will lose power, which is the main issue that concerns NEM customers. Due to the frequent blackouts in the national electricity network, backup batteries are needed and are considered essential to the functioning of net metering in Lebanon [15]. Because of this, hybrid solar systems take the 
advantages of both grid-tied (NEM) and off-grid systems and are recommended to be used in Lebanon to overcome the problem of Frequent Power Outages.

A dual-type inverter with special settings harmonized with the Lebanese grid parameters is needed to implement a hybrid solar system. The transfer relay that disconnects and reconnects the inverter to the grid can be either internal or external (Table 2 ). The dual inverter accepts a wider fluctuation of grid voltage and frequency than a purely grid-dependent inverter [13].

Table 2. Recommended settings for grid tied Inverter - CEDRO Project [13].

\begin{tabular}{|c|c|c|c|c|c|c|}
\hline \multicolumn{7}{|c|}{ RECOMENDED SETTINGS FOT NTERCONNECTED NET METERED RENEWABLE ENERGY MICRO POWER PLANTS WITH INVERTERS } \\
\hline TYPE OF PLANT & $\begin{array}{l}\text { REFERENCES DIAGRAM } \\
\text { (SINGLE PHASE) }\end{array}$ & $\begin{array}{l}\text { RATED } \\
\text { CURRENT }\end{array}$ & DISCONNECTION MEANS & $\begin{array}{l}\text { VOLTAGE } \\
\text { TOLERANCE }\end{array}$ & $\begin{array}{l}\text { FREQUENCY } \\
\text { TOLERANCE }\end{array}$ & $\begin{array}{c}\text { TRIP } \\
\text { DESCONNECTION } \\
\text { TMEE } \\
\end{array}$ \\
\hline $\begin{array}{l}\text { B1: Grid } \\
\text { dependent }\end{array}$ & $\frac{Y Q X}{\frac{1}{T}}$ & $\begin{array}{c}\text { Nominal } \\
\text { power }\end{array}$ & $\begin{array}{l}\text {-Inverter embedded stop } \\
\text { function } \\
\text {-Inverter extemal switch } \\
\text {-External Transfer switch }\end{array}$ & $\begin{array}{l}>0,80 \mathrm{Um} \\
<1,15 \mathrm{Um}\end{array}$ & $\begin{array}{l}>45 \mathrm{~Hz} \\
<55 \mathrm{~Hz}\end{array}$ & $<2 \mathrm{~s}$ \\
\hline
\end{tabular}

\subsection{Frequency Fluctuations}

Frequency drift, upwards or downwards, in a power system is the main indicator of the momentary imbalance between generation and demand. If at any instant, power demand exceeds supply, then the system frequency falls. Conversely, if the power supply exceeds demand, the frequency rises. The system frequency fluctuates continuously in response to the changing demand and due to the practical impossibility of generation being controlled to instantaneously track all changes in demand [16]. Future power system security will be challenged by the increasing penetration of non-synchronous RES. With high penetration levels of RES, the power system's dynamic complexity increases, and the system frequency control becomes a challenging task [17].

In the case of Lebanon, the frequency of the grid is always fluctuating due to high demand and lack of electricity supply. The National Control Center (NCC) dispatchers in EDL often seek to manually handle and monitor grid frequency variations by switching on and off some medium voltage feeders. These interventions from the dispatchers are relatively slow and cause some disturbances to the electrical network. Any severe or sudden increase or decrease in frequency will cause a partial or total collapse of the grid (total blackout).

\subsection{Voltage Instability}

Voltage stability of networks is still a major issue with major blackouts having recently occurred. Voltage stability refers to the capability of the power system to sustain constant voltage at all buses after being subjected to a disturbance from a given initial operating point [18].

Voltage disturbances are swings in supply voltage, which may be small due to marginal load switching and may be significant due outage of generation machine or presence of traveling surge on the power lines. Such changes would negatively affect the performance of the appliances (like light dimming or inability of starting an induction motor). The effect depends mainly on the value and the duration time of the change.

\subsection{Electrical Back Feed (Hawaii Case)}

The incentive policy of Hawaii Electrical CO. has set up a generous NEM program, which leads to the overbuilding of PV systems. Because the peak solar power production 
occurs around mid-day between 10:00 and 14:00, causing the grid to be flooded with solar electricity. The grid is not designed to deal with such a situation. In 2013, Hawaiian Electrical network is experienced enough PV solar coming onto an increasing quantity of circuits to back-feed power into their distribution grid on sunny days, and to drive systemwide demand curves below zero on peak days. Excess energy from a high influx of PV can back-feed into the circuits, causing overvoltage, reverse overloading, and other problems [19]. This over generation increased the voltage on the power lines and caused disturbances on household appliances and the utility's equipment.

This drop in demand highlighted the solar surplus that was sent to the grid, showing the difference in electricity demand and the supply from solar energy throughout the day. Solar generation in several US states (California and Arizona etc.) has started to cause significant variations in supply and demand curves. The result is drawing a "duck curve" (sometimes the duck's belly hits bottom).

In 2015, the Hawaiian Electric Co. decided to stop offering the state's most popular solar incentive program of NEM, which credits solar owners the full retail rate for any excess energy their systems send to the grid and replaced the NEM program with less attractive options [20].

\section{CONFLICTS OF INTEREST}

The authors declare that there is no conflict of interests regarding the publication of this paper.

\section{REFERENCES}

[1] United Nations Development Programme (UNDP) / CEDRO. (2018). Sustainable Energy for Lebanese Villages and Communities: The Village 24 Initiative. https://data2.unhcr.org/en/documents/details/66473 (accessed on 10/26/2020)

[2] United Nations Development Programme (UNDP) / CEDRO. (2017). Guidelines On Net - Metering: The Case Of Lebanon. https://data2.unhcr.org/en/documents/details/65011 (accessed on 10/26/2020)

[3] Qazi, S. (2017). Chapter 2 - Fundamentals of Standalone Photovoltaic Systems. In: Standalone Photovoltaic (PV) Systems for Disaster Relief and Remote Areas, S. Qazi, ed., Elsevier, pp: 31-82. DOI: 10.1016/B978-0-12-803022-6.00002-2.

[4] Pakkiraiah, B., and Sukumar, G. D. (2016). Research Survey on Various MPPT Performance Issues to Improve the Solar PV System Efficiency. Journal of Solar Energy, 2016, 8012432. DOI: 10.1155/2016/8012432.

[5] Kalogirou, S. A. (2013). Solar energy engineering: processes and systems, Academic Press.

[6] Eremia, M., and Shahidehpour, M. (2013). Handbook of electrical power system dynamics: modeling, stability, and control, John Wiley \& Sons.

[7] Shertukde, H. M. (2017). Distributed Photovoltaic Grid Transformers, CRC Press.

[8] Brunton, S. L., Rowley, C. W., Kulkarni, S. R., and Clarkson, C. (2010). Maximum Power Point Tracking for Photovoltaic Optimization Using Ripple- 
Based Extremum Seeking Control. IEEE Transactions on Power Electronics, 25(10), 2531-2540. DOI: 10.1109/TPEL.2010.2049747.

[9] Lundquist, J. (2001). On harmonic distortion in power systems. Chalmers University of Technology. http://citeseerx.ist.psu.edu/viewdoc/download?doi=10.1.1.531.4194\&rep=rep1\&t ype $=$ pdf $($ accessed on 10/26/2020)

[10] Raharja, L. P. S., Arief, Z., and Windarko, N. A. J. E. I. J. o. E. T. (2017). Reduction of total harmonic distortion (THD) on multilevel inverter with modified PWM using genetic algorithm. 5(1), 91-118.

[11] Trujillo, C., Velasco, D., Garcerá, G., Figueres, E., and Carranza, O. J. m. (2010). Analysis of Active Islanding methods for single phase inverters, in International Conference on Renewable Energies and Power Quality, Granada, Spain, 2010, pp. 1281-1286. DOI: 10.24084/repqj08.645

[12] Wrinch, M. C. (2008). Negative sequence impedance measurement for distributed generator islanding detection. University of British Columbia

[13] United Nations Development Programme (UNDP) / CEDRO. (2013). Photovoltaic Plants in lebanon. http://www.databank.com.lb/docs/Photovoltaic\%20plants\%20in\%20LebanonCedro\%202013.pdf (accessed on 10/26/2020)

[14] Lara, J. D. (2017). Net Metering Guidelines for Lebanon. http://www.cedroundp.org/content/uploads/event/170131112833676 Netmetering.pdf (accessed on $10 / 26 / 2020$ )

[15] The Lebanese Center for Energy Conservation (LCEC). (2016). The National Renewable Energy Action Plan (NREAP) for the Republic of Lebanon 2016-2020. http://lcec.org.lb/Content/uploads/LCECOther/161214021429307 NREAP_DEC 14.pdf (accessed on 10/26/2020)

[16] Short, J. A., Infield, D. G., and Freris, L. L. (2007). Stabilization of Grid Frequency Through Dynamic Demand Control. IEEE Transactions on Power Systems, 22(3), 1284-1293. DOI: 10.1109/TPWRS.2007.901489

[17] Ahmadyar, A. S., Riaz, S., Verbic, G., Chapman, A., and Hill, D. J. J. a. p. a. (2017). A Framework for Frequency Stability Assessment of Future Power Systems: An Australian Case Study. arXiv:1708.00739 [cs.SY]. https://arxiv.org/pdf/1708.00739.pdf (accessed on 10/26/2020)

[18] Heetun, K. Z., Abdel Aleem, S. H. E., and Zobaa, A. F. (2016). Voltage stability analysis of grid-connected wind farms with FACTS: Static and dynamic analysis. Energy and Policy Research, 3(1), 1-12. DOI: 10.1080/23317000.2015.1128369.

[19] GRID20/20 Inc. (2018). Managing DER Impacts, The GRID20/20 OptaNODE® Solution enables continuous increase. https://grid2020.com/private_files/GRID2020_DER_Case_Study.pdf (accessed on $10 / 26 / 2020$ )

[20] Cournoyer, C. (2016). End of Hawaii's Solar Credit Program Spells Trouble for Industry. https://www.governing.com/topics/transportation-infrastructure/tnshawaii-solar.html (accessed on 10/26/2020) 
Article copyright: (C) 2020 Issam Shabani and Mohammad Chaaban. This is an open access article distributed under the terms of the Creative Commons Attribution 4.0 International License, which permits unrestricted use and distribution provided the original author and source are credited.

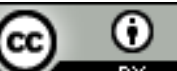

